\title{
Predicting morbidity and mortality using automated milk feeders: A scoping review
}

\author{
Jannelle Morrison, ${ }^{1} \oplus$ David L. Renaud, ${ }^{1} \odot$ Kathryn J. Churchill, ${ }^{1}$ Joao H. C. Costa, ${ }^{2} \odot$ Michael A. Steele, ${ }^{3} \oplus$ \\ and Charlotte B. Winder ${ }^{1 *}$ (1) \\ ${ }^{1}$ Department of Population Medicine, University of Guelph, Guelph, ON, Canada N1G 2W1 \\ ${ }^{2}$ Department of Animal and Food Science, University of Kentucky, Lexington 40506 \\ ${ }^{3}$ Department of Animal Biosciences, Animal Science and Nutrition, University of Guelph, Guelph, ON, Canada N1G 1Y2
}

\begin{abstract}
Automated milk feeders (AMF) are computerized systems that provide producers with a tool that can be used to more efficiently raise dairy calves and allow for easier implementation of a high plane of nutrition during the milk feeding phase. Automated milk feeders also have the ability to track individualized behavioral data, such as milk consumption, drinking speed, and the number of rewarded and unrewarded visits to the feeder, that could potentially be used to predict disease development. The objective of this scoping review was to characterize the body of literature investigating the use of AMF data to predict morbidity and mortality in dairy calves during the preweaning stage. This review lists the parameters that have been examined for associations with disease in calves and identify discrepancies found in the literature. Five databases and relevant conference proceedings were searched. Eligible studies focused on the use of behavioral parameters measured by AMF to predict morbidity or mortality in preweaned dairy calves. Two reviewers independently screened titles and abstracts from 6,675 records identified during the literature search. After title and abstract screening, 382 studies were included and then assessed at the fulltext level. Of these, 56 studies fed calves using an AMF and provided some measure of morbidity or mortality. Thirteen examined AMF parameters for associations with morbidity or mortality. The studies were completed in North America $(\mathrm{n}=6)$, Europe $(\mathrm{n}=6)$, and New Zealand $(\mathrm{n}=1)$. The studies varied in sample size, ranging from 30 to 1,052 calves with a median of 100 calves. All 13 studies included enteric disease as an outcome and 11 studies evaluated respiratory disease. Of the studies measuring enteric disease, 8 provided disease definitions $(\mathrm{n}=8 / 13,61.2 \%)$; however, for respiratory disease, only 5 provided a disease definition
\end{abstract}

Received September 15, 2020.

Accepted November 19, 2020.

*Corresponding author: winderc@uoguelph.ca
( $\mathrm{n}=5 / 11,45.5 \%)$. Disease definitions and thresholds varied greatly between studies, with 10 using some form of health scoring. When evaluating feeding metrics as indicators of disease, all 13 studies investigated milk consumption and 6 and 7 studies investigated drinking speed and number of rewarded and unrewarded visits, respectively. Overall, this scoping review identified that daily milk consumption, drinking speed, and rewarded and unrewarded visits may provide insight into early disease detection in preweaned dairy calves. However, the disparity in reporting of study designs and results between included studies made comparisons challenging. In addition, to aid with the interpretation of studies, standardized disease outcomes should be used to improve the utility of this primary research.

Key words: dairy calf, computerized feeder, automated milk feeder

\section{INTRODUCTION}

During the preweaning period, dairy calves are especially susceptible to infectious diseases (Svensson et al., 2003). A Canadian survey completed in 2015 identified a $6.4 \%$ mortality rate in preweaned female dairy calves, with $66 \%$ of these deaths occurring in the first $3 \mathrm{wk}$ of life (Winder et al., 2018). A similar study recently published in the United States found a similar calf mortality rate of 5\% (Urie et al., 2018a). The largest disease concerns in early life are enteric and respiratory diseases (Uetake, 2013). It is estimated that 23\% and $22 \%$ of calves are given an antimicrobial to treat diarrhea and respiratory disease, respectively (Windeyer et al., 2014). Respiratory disease and diarrhea in early life can lead to reduced growth and reduced future milk production (Svensson and Hultgren, 2008; Windeyer et al., 2014; Dunn et al., 2018), making the early detection of these diseases vital to calf health and productivity.

Group housing of dairy calves has increased in popularity in North America due to the perceived reduction in labor requirements and the increased animal welfare benefits (Costa et al., 2016; Medrano-Galarza et al., 
2017). However, as producers commonly detect disease in calves by monitoring subtle behavioral changes and differences in health indicators, these may be difficult to identify when calves are housed in groups. Producers often underdiagnose diarrhea and respiratory disease in group-housed calves, allowing these illnesses to go undetected for a longer period of time (Sivula et al., 1996; Medrano-Galarza et al., 2018). Often these diseases are not detected until significant clinical signs of disease are present (Cramer and Stanton, 2015). Due to the substantial overlap between human and livestock antimicrobials, there is a growing concern to decrease antimicrobial usage in dairy production to combat antimicrobial resistance (Langford et al., 2003). Earlier detection of disease may allow for interventions that are alternatives to antimicrobials. In group-housed calves, this could lead to reduced calf morbidity and improved growth in replacement heifers (McGuirk, 2008).

Automated milk feeders (AMF) collect data that could provide insight for producers to detect behavioral changes associated with the development of disease (Costa et al., 2021). Many allow producers to track a wide variety of individualized feeding metrics for each calf, including daily milk consumption, the speed of milk consumption, and the number of rewarded and unrewarded visits. Researchers have identified changes in specific behavioral parameters measured by AMF exhibited by calves before disease detection, such as decreased daily milk consumption, slower drinking speed, and a decreased number of unrewarded visits (Svensson and Jensen, 2007; Knauer et al., 2017; Sutherland et al., 2018). A recent study has also observed differences in these parameters when comparing clinical and subclinical disease in calves (Cramer et al., 2020). However, no formal synthesis of this literature has been performed. As AMF are increasing in popularity across Canada and the United States (Medrano-Galarza et al., 2017; Urie et al., 2018a), it is necessary to determine specific behaviors and thresholds for disease identification to allow producers to identify disease with more certainty.

A scoping review can be used to describe the main characteristics and identify possible knowledge gaps in a broad research field (Arksey and O'Malley, 2005). Scoping reviews differ from a traditional systematic review in that the authors do not analyze the quality of the included studies (Levac et al., 2010). These reviews are often common in emerging areas of research, where the number of published studies may be too small to undertake a full systematic review (Levac et al., 2010). The research surrounding AMF is limited, which lends itself to the use of a scoping review compared with a traditional systematic review. The objective of this scoping review was to characterize the body of literature investigating the use of AMF to predict morbidity and mortality in preweaned dairy calves. The review will list the parameters that have been examined for associations with disease and death in calves and discover gaps in knowledge.

\section{MATERIALS AND METHODS}

\section{Protocol and Registration}

A scoping review protocol was developed using the PRISMA extension for scoping reviews (PRISMA-ScR; Tricco et al., 2018). The protocol was established prior to the beginning of the study and was published in the University of Guelph Atrium (Morrison et al., 2019).

\section{Eligibility Criteria}

Only primary research was eligible for inclusion, including all types of analytical studies. The population was limited to dairy calves of any breed or sex that were fed using an AMF for all or a portion of the preweaning period. Studies must also have looked into associations between AMF feeding metrics and disease outcomes. To be included, publications must have been written in English and be at least 500 words in length. No geographical or date restrictions were placed other than the date restrictions imposed by the databases themselves.

\section{Information Sources}

Five electronic databases were searched to find potentially eligible articles: Medline via Ovid (1946 to present); CAB Direct via CAB (1920 to present); ProQuest via Agricultural and Environmental Science Database, Biological Science Database, Dissertations and Theses @ University of Guelph (1946 to present); Web of Science via Clarivate (1900 to present); and Scopus (1970 to present). American Association of Bovine Practitioners conference proceedings from 1997 to 2019 and World Buiatrics Congress proceedings from 2002 to 2019 were hand searched by a single reviewer.

\section{Literature Search}

The literature search was completed on September 6 and 7, 2019. We searched for records using a list of search terms related to dairy calves and the use of AMF, designed to maximize sensitivity. Table 1 shows the full search string used, which was then formatted appropriately for each of the database platforms. Records found in the searches from all databases were uploaded into Endnote X9 (Clairvate Analytics, Philadelphia, PA) reference management software, and duplicate refer- 
Table 1. Search string to identify primary research articles related to dairy calves and automated milk feeders

\begin{tabular}{ll}
\hline No. & Search terms \\
\hline 1 & bovine or dairy or veal or Holstein or Jersey or "brown swiss" or Guernsey or Ayrshire or "milking shorthorn" or heifer or bull \\
2 & calf or calves \\
3 & "milk feed*" or "calf rail" or "calf feed*" or "AMF" or "robotic feed*" or "computer feed*" or "computer controlled feed*" or \\
& "computer-controlled feed*" or "automatic feed*" or "automated feed*" or "milk feeding system" or "calf feeding system" or "robotic \\
& "automatic feeding system" or "automated feeding system or milk fed*" \\
& 1 AND 2 \\
5 & 1 AND 2 AND 3 \\
\hline
\end{tabular}

ences were identified and removed. Once deduplication was complete, references were uploaded to DistillerSR (Evidence Partners Inc., Ottawa, ON, Canada) where additional deduplication was performed. DistillerSR was then used for study screening and data extraction (Figure 1).

\section{Selection of Evidence}

Screening was conducted at 2 levels in DistillerSR in duplicate by 2 independent reviewers (JM, KC). First, articles obtained using the search terms underwent initial relevance screening based on title, abstract, and index terms. Articles were screened based on the following questions:

1. Is the title/abstract available in English?

2. Is the citation primary research?

3. Does the title/abstract/index terms describe a study investigating the use of automated feeder data as a predictor of morbidity or mortality in preweaned dairy calves?

Each reviewer performed a pre-test of the first 150 articles to ensure that both reviewers answered questions consistently. All questions were answered with "yes," "unclear," or "no," with the first 2 options leading to an article proceeding to the next level and the latter leading to exclusion. Agreement was at the form level. All disagreements between reviewers were resolved by both reviewers reaching a consensus together with discussion of all disagreements.

The full text was obtained for articles that met the inclusion criteria for the title/abstract screening. Fulltext screening was then performed using the following questions:

1. Was the full-text article/conference proceeding able to be obtained?

2. Does the full-text article/conference proceeding describe a primary research study?
3. Is the full-text article/conference proceeding available in English?

4. Does the full-text article/conference proceeding contain more than 500 words?

5. Does the full-text article/conference proceeding include the usage of AMF during the preweaning stage for dairy calves?

6. Does the full-text article/conference proceeding investigate morbidity or mortality in dairy calves?

7. Does the full-text article/conference proceeding investigate the use of AMF parameters as a predictor of morbidity or mortality in dairy calves?

All questions were answered using either "yes" or "no." A "no" answer to any question on the form led to exclusion of the article. An article with a "yes" answer to all questions was included for data extraction. Agreements were achieved at the question level, and all disagreements were resolved by both reviewers coming to a consensus.

\section{Data Extraction}

All articles included after the second level of screening were subject to data extraction. A pretest of the first 10 articles was completed to ensure that both reviewers had a similar understanding of the questions and consistency of completing the form. Two reviewers (JM, KC) performed data extraction independently in duplicate. All disagreements between reviewers were resolved by both reviewers reaching a consensus together through discussion of all disagreements. Data extracted from the full-text articles included the following:

1. General study characteristics (publication year, year and season study completed, and country where the study was completed)

2. Objective and hypothesis of study

3. Population of study: farm type, number of farms used, breed, sex, age, housing type, automatic 
feeder type (rail or feeder) and brand, sample size for study, number of calves in each pen

4. Automated feeder parameters examined

5. Morbidity and mortality information: how morbidity and mortality were measured, diseases measured and definitions, treatments reported

6. Other non-AMF parameters measured in the study
The full data extraction form is provided as Supplemental File S1 (https://doi.org/10.3168/jds.2020-19645).

\section{Synthesis of Results}

Extracted data from the final articles were exported from DistillerSR into a spreadsheet on Microsoft Excel
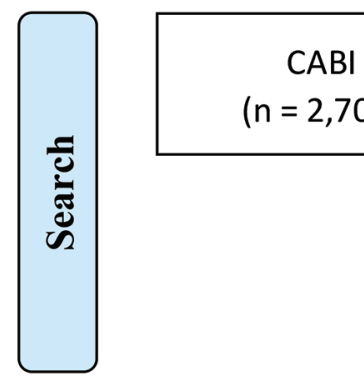

$\mathrm{CABI}$
$=2,700)$
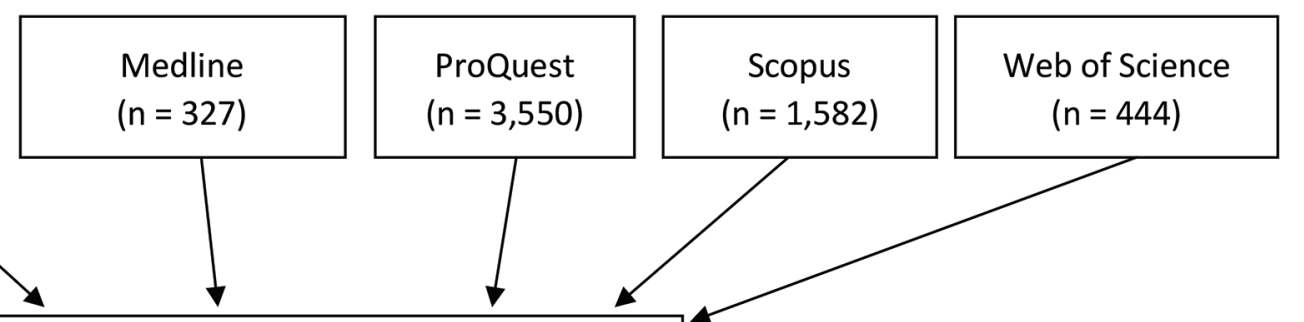

Records after duplicates removed

$$
(n=6,675)
$$
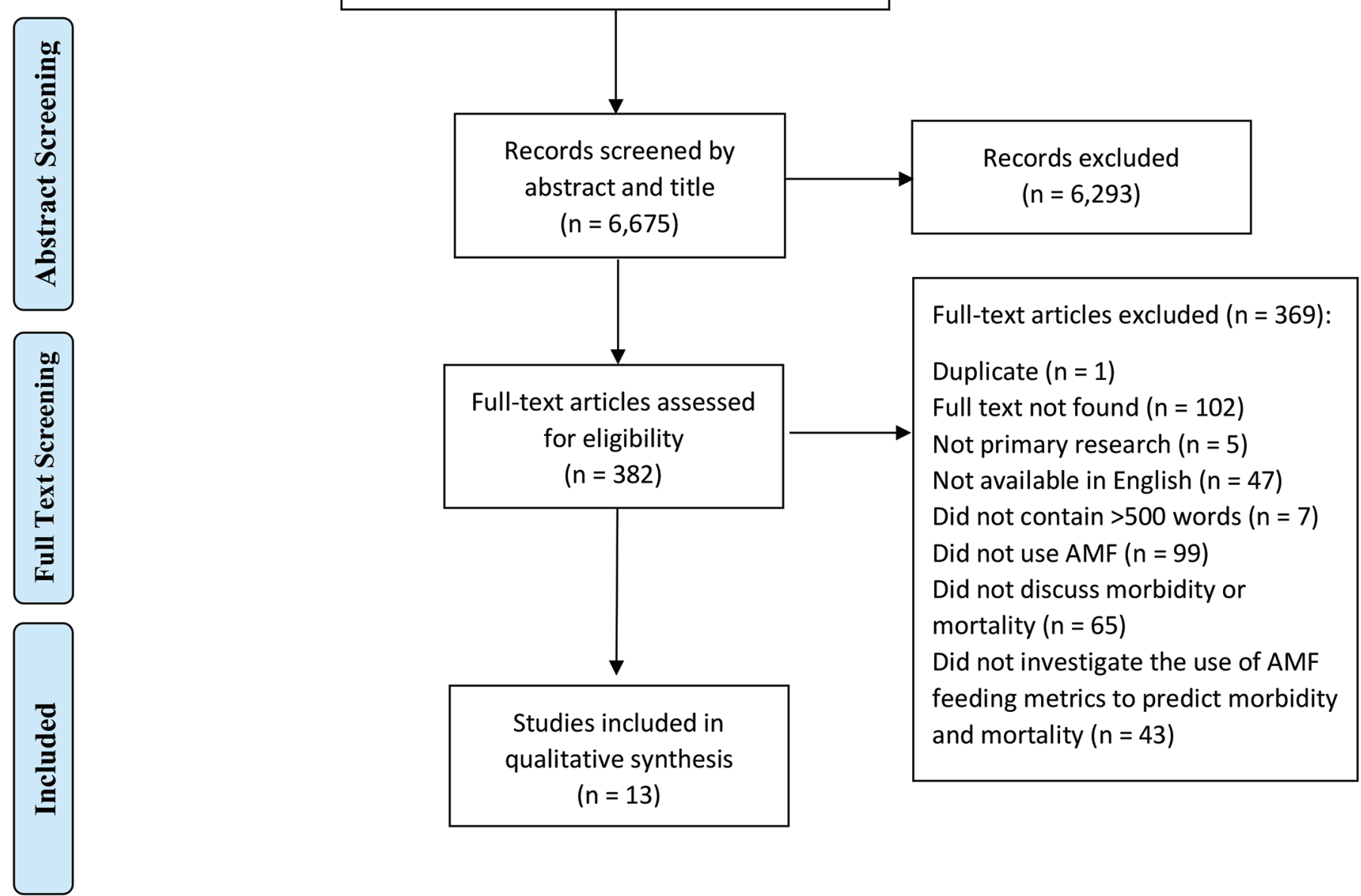

Figure 1. A Preferred Reporting Items for Systematic Reviews and Meta-Analysis (PRISMA) flow chart describing each step in the literature search process for a scoping review predicting morbidity and mortality using automated milk feeders (AMF). 
Table 2. Summary of the 13 references included in the data extraction for year study was published, country in which the study was completed, sample size of study, breed of calves in study, and age of calves in study

\begin{tabular}{|c|c|c|c|c|}
\hline Study & Country & $\begin{array}{l}\text { Sample } \\
\text { size }\end{array}$ & Breed & Age \\
\hline Knauer et al. (2018) & United States & 1,052 & Not reported & $9 \pm 5 \mathrm{~d}$ to $55 \pm 8 \mathrm{~d}$ \\
\hline Knauer et al. (2017) & United States & 1,052 & Not reported & $9.1 \pm 5 \mathrm{~d}$ to $55.4 \pm 8.2 \mathrm{~d}$ \\
\hline Swartz et al. (2017) & United States & 30 & Not reported & $7 \mathrm{~d}$ to $55 \mathrm{~d}$ \\
\hline de Passillé et al. (2016) & Canada & 130 & Holstein & $6 \mathrm{~d}$ to $28 \mathrm{~d}$ \\
\hline Webb et al. (2015) & The Netherlands & 270 & Holstein & $14 \mathrm{~d}$ to $175 \mathrm{~d}$ \\
\hline Wenge et al. (2014) & Germany & 100 & Holstein, additional breeds & $2 \mathrm{~d}$ to $21 \mathrm{~d}$ \\
\hline Borderas et al. (2009) & Canada & 64 & Holstein & 4 or $5 \mathrm{~d}$ to $21 \mathrm{~d}$ \\
\hline Roth et al. (2009) & Switzerland & 47 & Holstein, Jersey & $30 \mathrm{~d}$ to $85 \mathrm{~d}$ \\
\hline Svensson and Jensen (2007) & $\begin{array}{l}\text { Sweden and } \\
\text { Denmark }\end{array}$ & 68 & $\begin{array}{l}\text { Holstein, Brown Swiss, } \\
\text { additional breeds }\end{array}$ & $10 \mathrm{~d}$ to weaning \\
\hline Maatje et al. (1993) & The Netherlands & 400 & Holstein & $7 \mathrm{~d}$ to slaughter \\
\hline
\end{tabular}

for Mac (Microsoft Corp., Redmond, WA). Descriptive statistics were then calculated to summarize the data.

\section{Charting Process}

The studies were described using the PRISMA flowchart (Liberati et al., 2009; Figure 1). Frequency tables were constructed to summarize the included studies. The PRISMA extension for scoping reviews was used as a framework for this scoping review (Tricco et al., 2018).

\section{RESULTS}

\section{Selection of Sources of Evidence}

The initial search returned 8,603 references. After the deduplication process, 6,675 unique references were included for title/abstract screening. During this first level of screening, 6,293 references were deemed irrelevant and excluded. During the second level of full-text screening, another 369 references were excluded, with reasons described in Figure 1. This left a total of 13 references included in the scoping review, which underwent data extraction. The flow of articles through the screening process is described in Figure 1.

\section{Results from Included Studies}

Study-Level Characteristics. Table 2 shows the country in which each study was conducted. Six studies each were conducted in Europe $(\mathrm{n}=6 / 13,46.2 \%)$ and North America ( $\mathrm{n}=6 / 13,46.2 \%)$. In Europe, 2 studies were done in the Netherlands $(\mathrm{n}=2 / 13,15.4 \%)$, and 1 study was completed in each of the following coun- tries: Denmark $(\mathrm{n}=1 / 13,7.7 \%)$, Germany $(\mathrm{n}=1 / 13$, $7.7 \%)$, Ireland $(\mathrm{n}=1 / 13,7.7 \%)$, Sweden $(\mathrm{n}=1 / 13$, $7.7 \%)$, and Switzerland $(\mathrm{n}=1 / 13,7.7 \%)$. From North America, 4 studies were conducted in the United States $(\mathrm{n}=4 / 13,30.8 \%)$ and 2 in Canada $(\mathrm{n}=2 / 13,15.4 \%)$. There was 1 additional study from New Zealand $(\mathrm{n}=$ $1 / 13,7.7 \%)$.

The majority of the studies were published between 2010 and $2019(\mathrm{n}=9 / 13,69.2 \%)$; only 3 studies were published from 2000 to $2010(\mathrm{n}=3 / 13,23.1 \%)$, and 1 study was published in 1993. Five of the studies did not report the year in which the study was conducted (n $=5 / 13,38.5 \%$ ). Of the other 8 studies, 7 of the studies were completed between 2012 and $2016(\mathrm{n}=7 / 13$, $53.8 \%$ ), and 1 study was completed in $2005(\mathrm{n}=1 / 13$, $7.7 \%$ ). Seven of the included studies were completed on a research farm $(\mathrm{n}=7 / 13,53.8 \%)$, and 4 were completed on commercial farms $(\mathrm{n}=4 / 13,30.8 \%)$. Two studies did not report the type of farm on which the study was completed. All included studies were either observational (cohort or cross-sectional; $\mathrm{n}=8 / 13$, $61.5 \%)$ or experimental $(\mathrm{n}=5 / 13,38.5 \%)$.

The majority of studies had more than 1 breed of calves. The most common breed was Holstein-Friesian $(\mathrm{n}=11 / 13,84.6 \%)$, followed by Jersey $(\mathrm{n}=4 / 13$, $30.8 \%)$ and Brown Swiss $(\mathrm{n}=1 / 13,7.7 \%)$. Three studies included additional dairy breeds such as HolsteinFriesian $\times$ Belgian Blue-White, Danish Reds, Swedish Red and Whites, and Friesian-Hereford. In 3 studies, the breed of calves was not reported.

The most common AMF brand used in the studies was Forster-Technik (Engen, Germany; $\mathrm{n}=6 / 13$, $46.2 \%$ ), followed by DeLaval (Tumba, Sweden; $\mathrm{n}=$ 2/13, 15.4\%), A\&D Reid (Temuka, New Zealand; $\mathrm{n}=$ 1/13, 7.7\%), Holme \& Laue (Westerronfeld, Germany; 
Table 3. Summary of 13 references included in data extraction summarizing automated milk feeder (AMF) brand and parameters measured

\begin{tabular}{|c|c|c|}
\hline Study & AMF brand ${ }^{1}$ & Parameters measured $^{2}$ \\
\hline Sutherland et al. (2018) & A\&D Reid & Rewarded/unrewarded visits, total visits, milk consumption \\
\hline Knauer et al. (2017) & Forster-Technik & Drinking speed, rewarded/unrewarded visits, milk consumption \\
\hline Swartz et al. (2017) & Forster-Technik & Drinking speed, rewarded/unrewarded visits, milk consumption \\
\hline de Passillé et al. (2016) & DeLaval & Milk consumption \\
\hline Webb et al. (2015) & Not reported & Milk consumption \\
\hline Wenge et al. (2014) & Not reported & Milk consumption \\
\hline Borderas et al. (2009) & Not reported & Milk consumption \\
\hline Roth et al. (2009) & Forster-Technik & Milk consumption, concentrate consumption \\
\hline Svensson and Jensen (2007) & Deleval, Calvex & Drinking speed, rewarded/unrewarded visits, milk consumption \\
\hline Maatje et al. (1993) & Not reported & Drinking speed, rewarded/unrewarded visits, milk consumption \\
\hline
\end{tabular}

${ }^{1}$ Forster-Technik: Engen, Germany; A\&D Reid: Temuka, New Zealand; Urban: Wüsting, Germany; Holme \& Laue: Westerronfeld, Germany; DeLaval: Tumba, Sweden; Calvex: Højslev, Denmark.

${ }^{2}$ Drinking speed was measured in $\mathrm{mL} / \mathrm{min}$; rewarded/unrewarded visits were measured by count; milk consumption was measured in $\mathrm{mL} / \mathrm{d}$ or $\mathrm{L} / \mathrm{d}$; and concentrate consumption was measured in $\mathrm{g} / \mathrm{d}$.

$\mathrm{n}=1 / 13,7.7 \%$ ), Urban (Wüsting, Germany; $\mathrm{n}=1 / 13$, $7.7 \%$ ), and Calvex (Højslev, Denmark; $\mathrm{n}=1 / 13,7.7 \%$; Table 3). Two studies did not report the brand of AMF.

Sample Size. The sample size of the studies ranged from 30 to 1,052 calves, with an average of 328 calves and a median of 100 calves. Three studies included a sample size or post hoc power calculation $(\mathrm{n}=3 / 13$, $23.1 \%)$.

Metrics Assessed by the AMF. Studies often measured more than 1 behavioral parameter provided by the AMF. Daily milk consumption (in $\mathrm{mL} / \mathrm{d}$ or L/d), defined as the volume of milk consumed daily by each calf, was measured in all studies (Table 4). The number of times per day a calf visited the AMF for a meal in which the calf was either awarded a milk meal (rewarded visit) or turned away with no milk provision (unrewarded visit) was measured (visits per day) in 7 studies $(\mathrm{n}=7 / 13,53.8 \%$; Table 4$)$. Average daily drinking speed $(\mathrm{mL} / \mathrm{min}$ or $\mathrm{L} / \mathrm{min})$, defined as the volume of milk each calf drank per minute averaged daily, was observed in 6 of the references $(n=6 / 13,46.2 \%$; Table 4). Total visits to the AMF (rewarded and unre-

Table 4. Number of studies that found associations with enteric and respiratory disease and the automated milk feeder parameters associated

\begin{tabular}{lccc}
\hline Item $^{1}$ & Total & Enteric & Respiratory \\
\hline Milk consumption & 13 & 13 & 11 \\
Drinking speed & 6 & 6 & 6 \\
Reward/unrewarded & 7 & 7 & 6 \\
$\quad$ visits & & &
\end{tabular}

${ }^{1}$ Milk consumption was measured in $\mathrm{mL} / \mathrm{d}$ or $\mathrm{L} / \mathrm{d}$; drinking speed was measured in $\mathrm{mL} / \mathrm{min}$; and rewarded/unrewarded visits were measured by count. warded visits combined) was evaluated in 1 study $(\mathrm{n}=$ $1 / 13,13.7 \%$ ). Two studies used automated concentrate feeders and reported concentrate consumption as an additional feeding metric $(\mathrm{n}=2 / 13,15.4 \%)$.

Definitions of Morbidity. The most common method used by researchers to detect illness in calves was health scoring, which was completed in 10 of the studies $(\mathrm{n}=10 / 13,76.9 \%)$. Four of the studies $(\mathrm{n}=$ $4 / 13,30.8 \%$ ) used subjective evaluations, which were not further defined and were performed by farm staff. Treatment records and subjective veterinary assessment were used in 1 study each. The majority of studies used more than 1 of these approaches to detecting illness in calves (Table 5). The frequency of illness detection varied throughout the studies. For studies that used health scoring, 8 studies completed scoring either twice daily or daily ( $\mathrm{n}=8 / 10,80 \%$ ), and the other 2 studies evaluated health at a lower frequency of either twice weekly (for $8 \mathrm{wk}$ ) or bimonthly (for $7.5 \mathrm{wk}$ ) throughout the study period. For studies that used subjective evaluations by farm staff, 4 studies took these measurements daily $(\mathrm{n}=4 / 5,80 \%)$, and a single study completed them bimonthly. One study used subjective assessment by a veterinarian, which was performed twice a week. One study used treatment records in combination with health scoring and subjective evaluations by farm staff.

The personnel that conducted the health assessments varied between studies, with 5 studies using a technician to determine health outcomes $(\mathrm{n}=5 / 13,38.5 \%)$. In 4 studies, the researchers performed the assessments (n $=4 / 13,30.8 \%)$. Farm staff were used in 3 studies $(\mathrm{n}=$ $3 / 13,23.1 \%$ ), and veterinarians were used in 3 studies $(\mathrm{n}=3 / 13,23.1 \%)$. Outcome assessor was not reported in 3 of the studies $(\mathrm{n}=3 / 13,23.1 \%)$. Three studies 


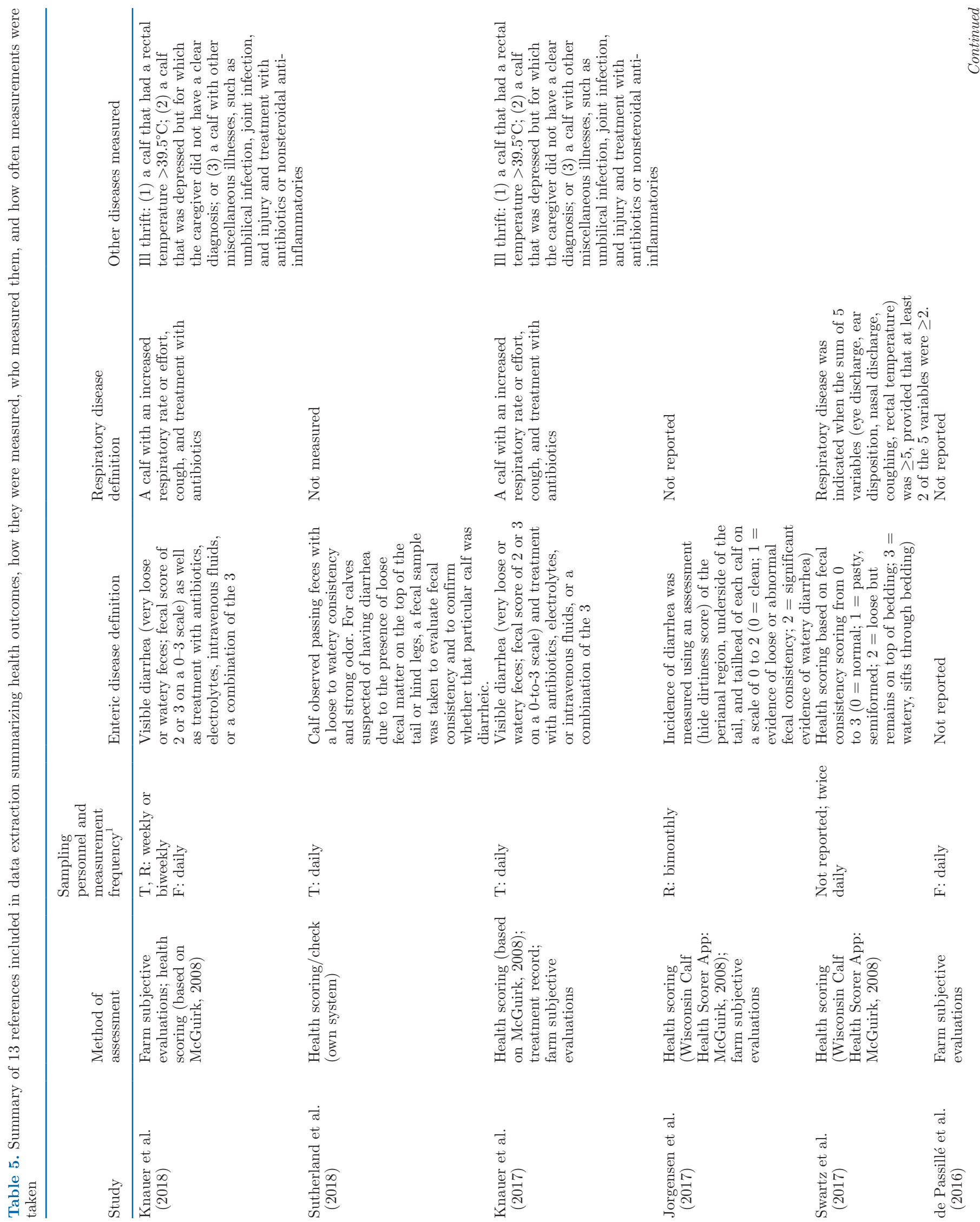


Morrison et al.: HEALTH AND AUTOMATED MILK FEEDERS

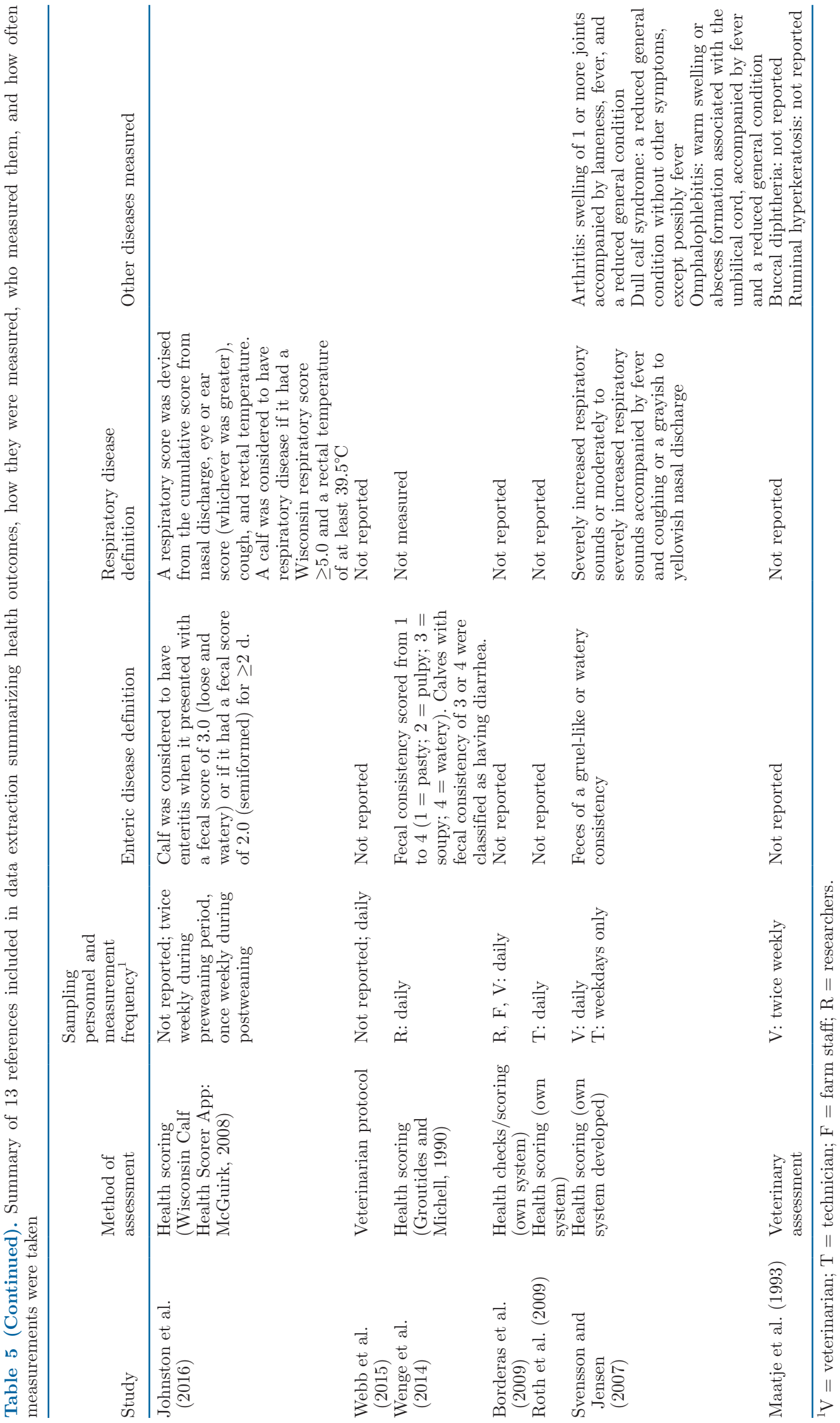


used more than 1 type of outcome assessor throughout the study $(\mathrm{n}=3 / 13,23.1 \%)$.

Studies measured a variety of diseases; however, all studies reported enteric disease as a specific outcome (Table 4). Five of these studies did not provide a case definition; however, of the 8 studies that did, all used some version of health scoring. Five studies used an adapted version of the scoring system developed by McGuirk (2008), which scored calves on a 0-to-3 scale, where $0=$ normal fecal consistency and $3=$ watery feces (McGuirk, 2008). Two studies developed their own health scoring and provided diarrhea definitions as "feces of a gruel-like or watery consistency" (Svensson and Jensen, 2007) or "a calf observed passing feces with a loose to watery consistency and strong odor" (Sutherland et al., 2018). One study used a scoring system developed by Groutides and Michell (1990) in which enteric disease was scored on a 1-to-4 scale, where a calf with a fecal consistency of 3 or 4 was classified as having diarrhea (Wenge et al., 2014).

Respiratory disease was reported as an outcome in 11 of the studies ( $\mathrm{n}=11 / 13,84.6 \%$ ), and a case definition was provided in 5 of these studies. Four of the 5 studies used an adapted version of a respiratory scoring system developed by McGuirk and Peek (2014). This scoring system, much like the system used for enteric disease, ranks different health variables on a 0 -to- 3 scale, where $0=$ healthy and $3=$ the least healthy (McGuirk and Peek, 2014). Swartz et al. (2017) used the sum of 5 health variables to identify a calf with respiratory disease: eye discharge, ear disposition, nasal discharge, coughing, and rectal temperature. A calf would need to accumulate a score $\geq 5$ to be classified as having respiratory disease provided that at least 2 of the 5 variables were $\geq 2$ using the 0 -to- 3 health scoring system (Swartz et al., 2017). Johnston et al. (2016) used the same variables as Swartz et al. (2017) to create a respiratory score for each calf; however, they considered any calf with a score $>5$ to have respiratory disease. Knauer et al. $(2017,2018)$ deemed a calf to have respiratory illness when calves had at least increased respiratory rate or effort and cough accompanied by an antimicrobial treatment. The sixth study developed their own health scoring method in which respiratory disease was defined as "severely increased respiratory sounds or moderately to severely increased respiratory sounds accompanied by fever and coughing or a greyish to yellowish nasal discharge" (Svensson and Jensen, 2007).

Ill thrift is described in 2 studies $(\mathrm{n}=2 / 13,15.4 \%$; Knauer et al., 2017, 2018) and was defined as a calf that had either an rectal temperature, a depressed attitude without an apparent diagnosis, or any other miscellaneous illness. Additional diseases of arthritis, dull calf syndrome, and omphalophlebitis were reported in
Svensson and Jensen (2007). Maatje et al. (1993) also reported buccal diphtheria and ruminal hyperkeratosis.

Study Statistics. For the tables describing associations with feeding behaviors (Tables 6-9), data were included only if the value was reported in text or in a table; graphical data were not included. Studies also needed to report a measure of variance for data to be included. The following paragraph includes only the results presented in Tables 6 through 9. The 4 included outcomes were drinking speed, milk consumption, rewarded visits, and unrewarded visits. Out of the 6 studies that evaluated drinking speed, 4 studies included relevant statistics ( $\mathrm{n}=4 / 6,66.7 \%$; Table 6$)$. All 4 of these studies compared sick calves with a healthy control and found that sick calves drank slower compared with their healthy matched control. All studies reported milk consumption as a behavioral parameter in their study; however, only 6 studies included full reporting of data $(\mathrm{n}=6 / 13,46.2 \%)$ and were included in the statistics table (Table 7). These 6 studies found a decrease in daily milk consumption of sick calves compared with their healthy controls. Although 7 studies looked into rewarded visits at the AMF, only 3 of these studies fully reported outcome data for rewarded visits ( $\mathrm{n}=3 / 7,42.9 \%$; Table 8). Results of these 3 studies are mixed, with 1 study reporting that sick calves had more rewarded visits to the feeder and 2 studies reporting that sick calves had fewer rewarded visits to the feeder. Last, for unrewarded visits, 7 studies included this parameter; however, only 4 studies fully reported outcome data $(\mathrm{n}=4 / 7,57.1 \%$; Table 9$)$. All 4 studies reported sick calves having fewer unrewarded visits to the AMF compared with their healthy counterparts. Regardless of behavioral parameter being analyzed, all studies used a multivariable mixed model analysis or a univariate model as their final model.

\section{DISCUSSION}

The scope of research involving the usage of AMF to predict morbidity and mortality is limited. Using the scoping review methodology, we identified behavioral parameters measured by AMF that have been examined in the literature for their ability to predict disease in preweaned dairy calves. The studies identified in this review covered a wide range of western countries; however, this review was limited to studies available in English. This may have limited the scope of this review.

\section{Sample Size}

Only 3 of the included studies performed a sample size or power calculation (Knauer et al., 2017, 2018; Sutherland et al., 2018); the remaining 9 studies did not 


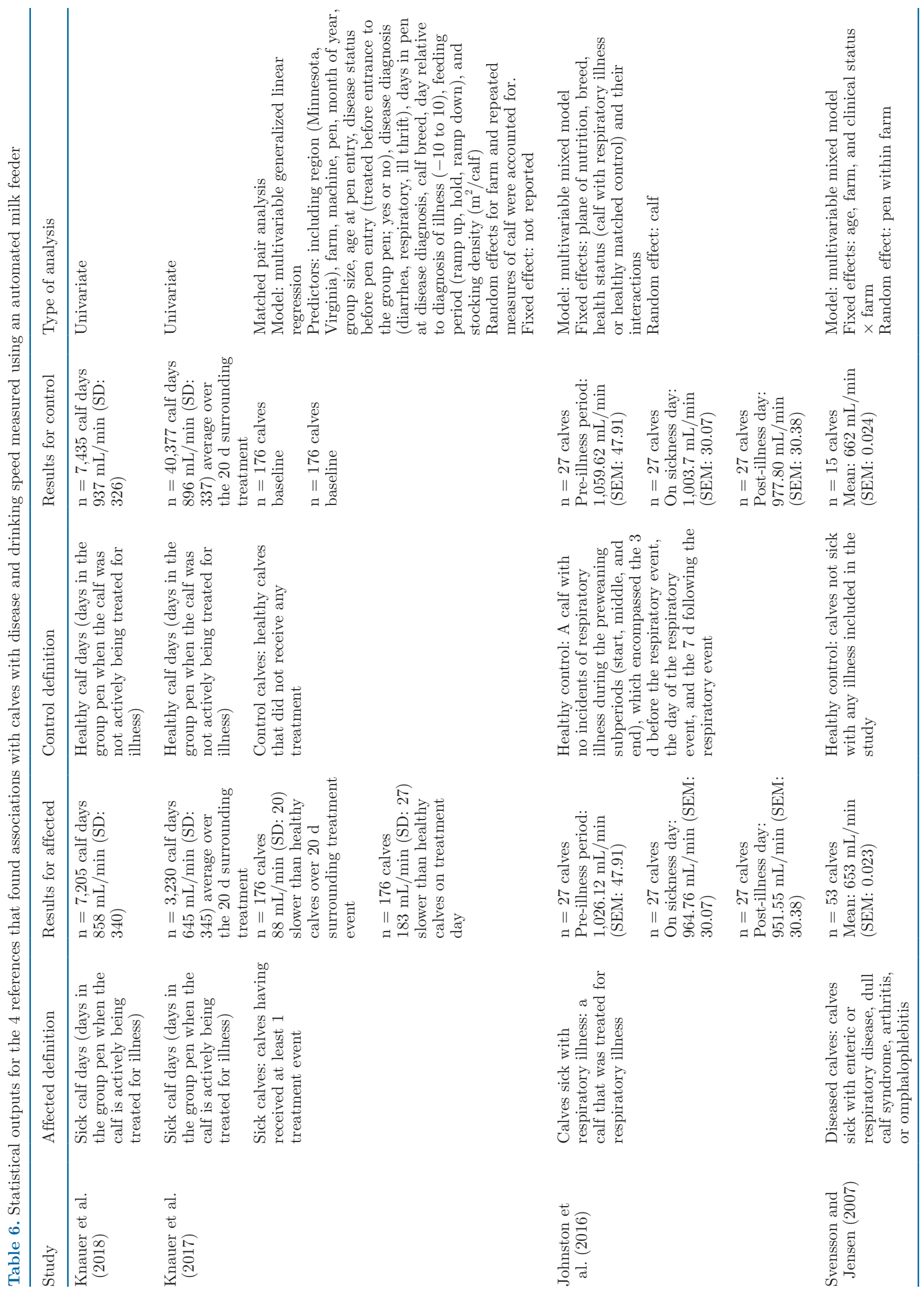




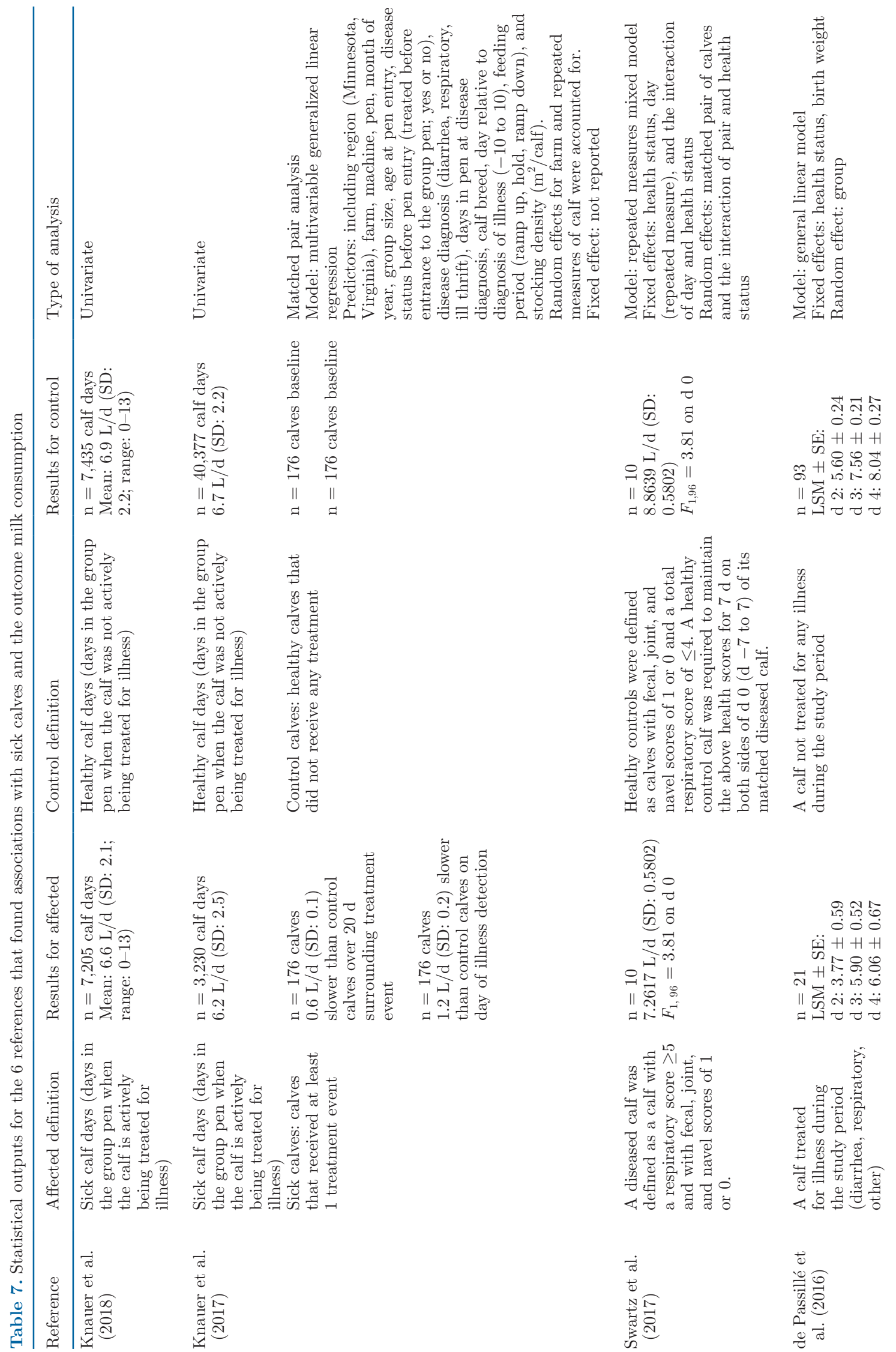


Morrison et al.: HEALTH AND AUTOMATED MILK FEEDERS

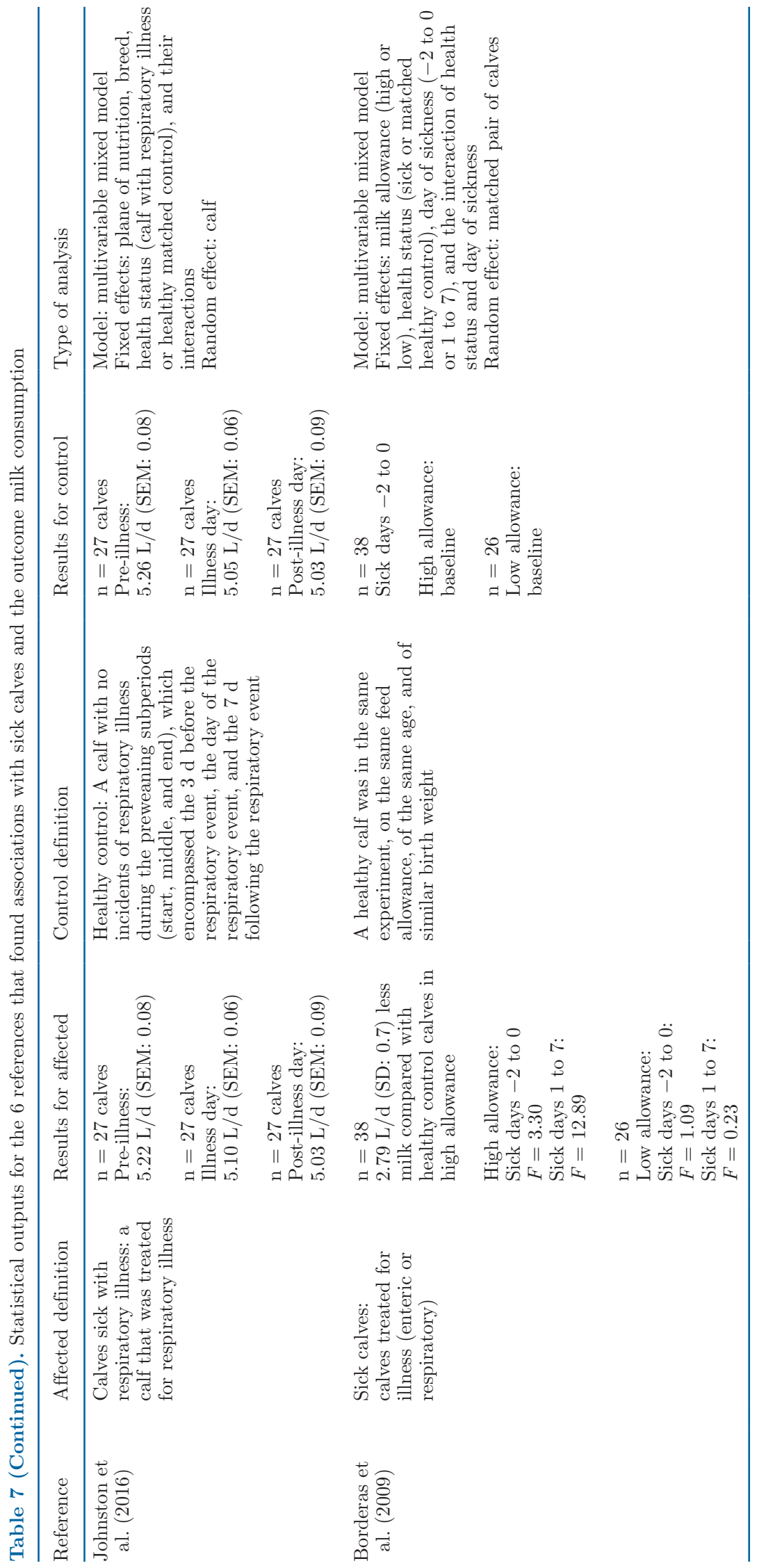




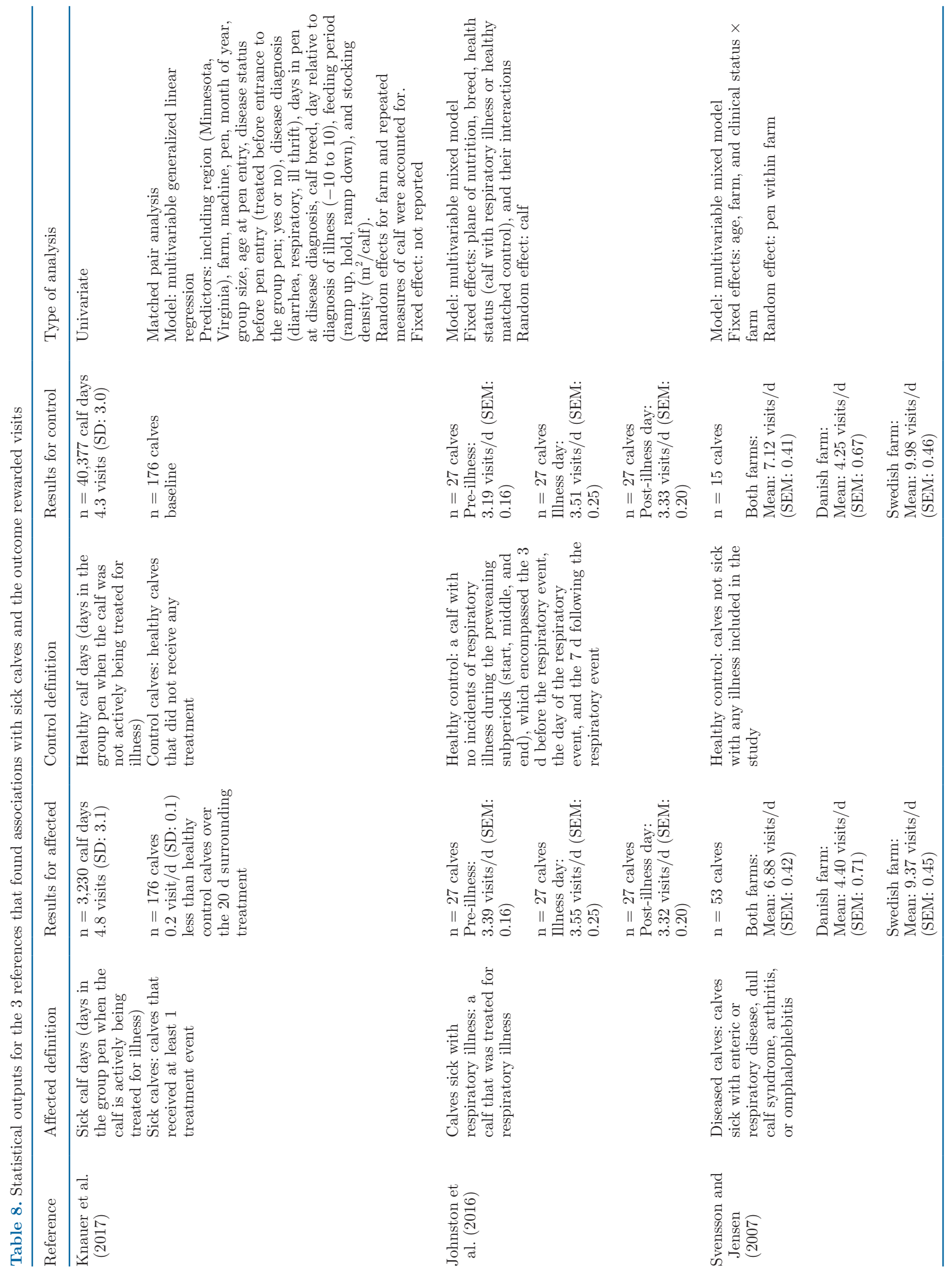




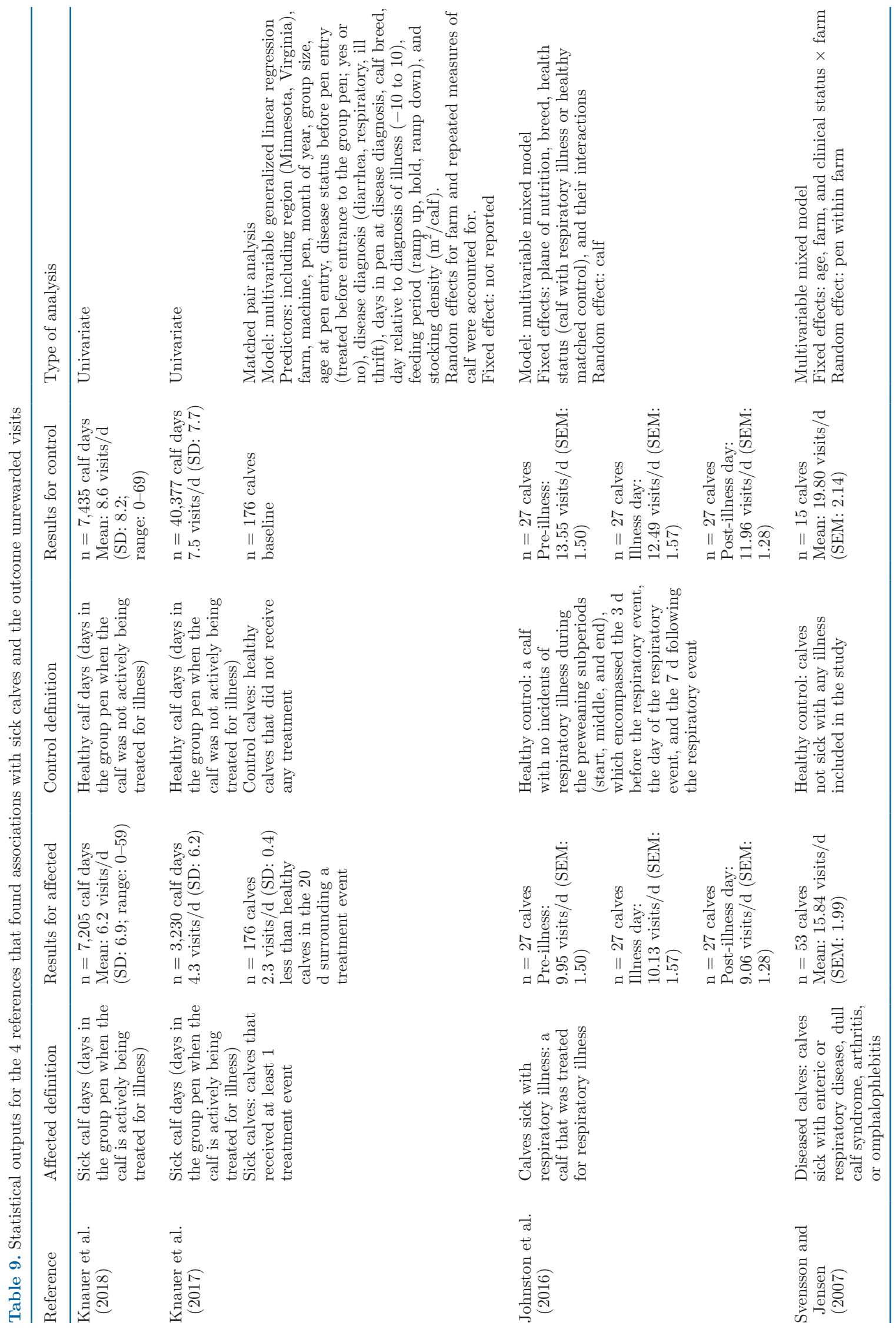


report completing either a sample size or power calculation. Two of those that reported a power calculation based it on detection of a milk intake difference of $1 \mathrm{~L} / \mathrm{d}$ between sick and healthy calves (80\% power and $95 \%$ CI; Knauer et al., 2017, 2018). The third study did not specify what their calculation was based on. Calculation of sample size is an essential component of analytic study design (Charan and Kantharia, 2013). Without this information, it is difficult to assess whether the study was adequately powered to determine the nature of the relationship between the predictor variables and the outcome of interest and can lead to a type II error (Charan and Kantharia, 2013; Johnson et al., 2015). That said, a sample size calculation does require an estimation of the nature of the association. Jorgensen et al. (2017) deemed the body of literature in this area of research as too small to have a valid estimation and instead opted to enroll as many farms as logistically possible, leading to their sample size of 925 calves, the second largest of the included studies.

A recent review of animal health studies showed that only $16 \%$ of studies reported a sample size justification, and only $12 \%$ reported a sample size calculation (Winder et al., 2019). Due to the high percentage of studies lacking the proper reporting of these calculations, it is hard to speculate whether lack of inclusion was due to researchers simply not completing a sample size calculation or due to improper reporting techniques leading to it being left out of the final paper. Consideration of and reporting sample size justification should be included in future research.

\section{AMF Parameters}

It is interesting that all studies using AMF had access to a wide variety of parameters (daily milk consumption, drinking speed, rewarded and unrewarded visits); however, some of the studies did not examine all of these parameters. Although it is possible that certain parameters may not have been considered by researchers, none of the included studies have a published study protocol, so it is not possible to determine which parameters were specified a priori to evaluate. Publication of a study protocol before the commencement of a research trial allows researchers and reviewers alike to obtain a better understanding of the objectives and more appropriately frame the outcomes of the research. Study protocols also help reduce selective reporting bias, which often occurs in animal studies when some but not all parameters measured by researchers selectively do not make it to publication (ter Riet and Bouter, 2016).

It has been shown that calves will decrease milk consumption when ill, as this is one of the first signs of disease (Johnson, 2002). Reduction in feeding behaviors is thought to be an adaptive response to infection, mediated by proinflammatory cytokines in an attempt to maintain the calf's homeostasis (Johnson, 2002). Therefore, it is not surprising that all studies included in this review measured milk consumption as a behavioral parameter to predict disease in calves. Knauer et al. (2017) found a decrease in milk consumption when comparing treated calves with a healthy control, both leading up to a treatment event and persisting up to $10 \mathrm{~d}$ post-treatment. When these results were then stratified for individual diseases, only calves sick with enteric disease were shown to drink significantly less than their healthy matched controls (Knauer et al., 2017). Interestingly, Svensson and Jensen (2007) found no difference in milk consumption between sick calves and their healthy controls. This discrepancy in results compared with the other included studies may be due to differences in daily milk allowance and individual meal size programmed into the AMF. Borderas et al. (2009) found that calves fed a high plane of milk nutrition $(12 \mathrm{~L} / \mathrm{d})$ decreased milk intake when sick; however, calves on a low plane of milk nutrition $(4 \mathrm{~L} / \mathrm{d})$ did not decrease milk consumption in the days leading up to illness. This may be due to the calves with a low plane of milk nutrition being fed such a small daily milk allowance that the motivation for milk overpowered the normal sickness response (De Paula Vieira et al., 2008).

Drinking speed is thought to decrease when calves experience illness (Maatje et al., 1993), so it is interesting that it was evaluated in only 6 of the 13 included studies. Knauer et al. (2017) found a decrease in average drinking speed when comparing sick calves and healthy controls; however, when they stratified for illness, this relationship was much more pronounced in calves with enteric disease compared with calves with respiratory illness. Johnston et al. (2016) had a similar finding in which calves with enteric disease had a decrease in drinking speed compared with their healthy controls. Knauer et al. (2018) also found that drinking speed was the most sensitive AMF parameter in helping to identify calves with respiratory or enteric disease before detection by farm personnel, which aligns with Maatje et al. (1993). However, not all included studies found a difference in drinking speed between sick and healthy calves. Swartz et al. (2017) found no difference in drinking speed between calves with respiratory illness and a healthy control. Svensson and Jensen (2007) did not separate specific diseases and reported no significant differences in drinking speed when comparing sick calves and healthy calves. Svensson and Jensen (2007) included a small number of calves per pen (5-10 calves), which may have decreased competition for the AMF. When a small number of calves are kept in each 
pen, this reduces competition for the feeder and allows sick calves to better access the AMF (Svensson and Jensen, 2007). Other differences in disease etiology and extraneous factors may have also contributed to these differences. Another potential explanation of the discrepancy in results could be related to the lack of proper validation of drinking speed measurement in individual AMF machines. Currently, one cannot be sure that the drinking speed measured in one study is equal to that in another study; it can only be assumed that all machines are calibrated properly.

The third major AMF parameter mentioned in 7 of the included studies was the number of visits to the feeder, whether rewarded and unrewarded. When a calf enters the AMF to consume a meal, it is either given a milk provision (rewarded visit) or turned away without being supplied any milk (unrewarded visit). Whether a calf is provided milk or not is based on the amount of time that has elapsed since the calf last drank; this amount of time changes depending on plane of nutrition and individual farm protocols (Rosenberger et al., 2017). Knauer et al. (2017) and Svensson and Jensen (2007) found a decrease in unrewarded visits, but not rewarded visits, when comparing sick calves and healthy controls. This evidence suggests that ill calves are still motivated enough to visit the AMF, but not more than necessary (Knauer et al., 2017). A similar result was found by Sutherland et al. (2018) in which unrewarded visits were found to be a more sensitive predictor of enteric disease compared with rewarded visits. Interestingly, Swartz et al. (2017) found no difference in rewarded or total visits to the AMF when comparing sick calves and a healthy control. This inconsistency of results between studies could be related to the differences in individual AMF machines. This review included a wide variety of different AMF brands, none of which have been properly validated to allow for proper comparison between these different models. Some machines may be more sensitive when a calf enters the machine, picking up more unrewarded visits than another machine. Without proper validation of the different AMF it is hard to properly compare results of each study. Nipple diameter and hose length in the AMF have also been shown to affect the number of rewarded and unrewarded visits to the feeder (Jensen and Holm, 2003). None of the studies included in this review reported any machine sizes or settings, further complicating comparison.

\section{Morbidity Definitions}

In this review, we found that there was a lack of consistent disease definitions used throughout many of the studies included. All included studies measured enteric disease; however, only 8 supplied a definition for disease. Of the 11 studies that measured respiratory disease, only 5 provided a disease definition. This limits comparisons between studies as well as quantitative synthesis. Lack of reporting of key study details is commonly found in synthesis work. A systematic review and meta-analysis looking at the efficacy of bacterial vaccines to prevent respiratory disease in swine also found a lack of proper outcome reporting, preventing them from including $25 \%$ of the studies in their network meta-analysis (Sargeant et al., 2019).

Five of the studies in our review used a scoring system developed by McGuirk (2008) for enteric disease and McGuirk and Peek (2014) for respiratory disease. Some studies altered the scoring system to better meet the needs of their trial. This led to variable (or not reported) disease definitions and thresholds, complicating comparison of these studies. Another option to further confirm diagnoses of respiratory disease would have been to implement lung ultrasonography. Lung ultrasonography in dairy calves has the ability to provide visual evidence of lung lesions caused by respiratory disease (Ollivett and Buczinski, 2016). The addition of lung ultrasonography could help increase the sensitivity and specificity of detecting respiratory illness in calves (Buczinski et al., 2014). Lung ultrasound combined with respiratory health scoring would provide researchers with a strong ability to properly predict respiratory disease (Cramer and Ollivett, 2019).

Included studies listed a variety of outcome assessors, including the researchers themselves, technicians, farm staff, and veterinarians. The majority of studies enlisted more than 1 of the above-listed personnel, with technicians being the most common. In studies using a form of health scoring, it was most commonly performed by a researcher or technician. Only in 1 study was the task of health scoring shared among researchers, veterinarians, and farm staff (Borderas et al., 2009). When farm staff assisted with the research, it was often in the form of farm subjective evaluations or producer records. There are potential drawbacks to using farm records because they may not be as accurate or valid as health scoring performed by trained technicians or researchers due to reporting differences, disease definitions, and subjectivity of farm staff. Only 1 (Knauer et al., 2017) of the included studies reported an evaluation for inter- or intrarater reliability. In addition, there was a wide variation in the frequency of disease measurements throughout the included studies. When health scoring is performed weekly or biweekly, there is an increased chance disease may be missed compared with daily scoring. Furthermore, performing health scoring on a daily basis provides the potential for disease to be discovered at an earlier time point. 
The Core Outcome Measures in Effectiveness Trials (COMET) initiative has been developed by researchers in the United Kingdom to help combat the current discrepancies in outcome reporting plaguing health research. The COMET initiative uses consensus methods to develop a core outcome set for many different human health conditions (Gargon et al., 2019). Researchers looking into diseases with a developed outcome set are implored to use these outcomes in their own research with hopes that it will improve the quality of outcome reporting in health research in the future (Gargon et al., 2019). Currently, the COMET initiative has not been expanded into animal health research. In the future, a database of standardized disease outcomes and definitions would increase the quality of outcome reporting in animal health research, in turn increasing the quality of conducted research.

\section{CONCLUSIONS}

The results of this scoping review provide insight into the breadth of research involving the usage of behavioral parameters measured by AMF to predict morbidity in dairy calves. Daily milk consumption, drinking speed, and rewarded and unrewarded visits may provide insight into early disease detection in preweaned dairy calves. Future research should consider the implementation of a priori research protocols in an effort to reduce reporting bias, including sample size justification. Standardization of health scoring and providing proper disease definitions and thresholds would allow for better comparison of included studies.

\section{ACKNOWLEDGMENTS}

Funding provided by the Food From Thought grant from the University of Guelph. The authors confirm that they have no conflicts of interest.

\section{REFERENCES}

Arksey, H., and L. O'Malley. 2005. Scoping studies: Towards a methodological framework. Int. J. Soc. Res. Methodol. 8:19-32. https:/ /doi.org/10.1080/1364557032000119616.

Borderas, T. F., J. Rushen, M. A. G. von Keyserlingk, and A. M. B. de Passille. 2009. Automated measurement of changes in feeding behavior of milk-fed calves associated with illness. J. Dairy Sci. 92:4549-4554. https://doi.org/10.3168/jds.2009-2109.

Buczinski, S., G. Forté, D. Francoz, and A. M. Bélanger. 2014. Comparison of thoracic auscultation, clinical score, and ultrasonography as indicators of bovine respiratory disease in preweaned dairy calves. J. Vet. Intern. Med. 28:234-242. https://doi.org/10.1111/ jvim. 12251.

Charan, J., and N. Kantharia. 2013. How to calculate sample size in animal studies? J. Pharmacol. Pharmacother. 4:303-306. https:// doi.org/10.4103/0976-500X.119726.

Costa, J. H., M. C. Cantor, and H. W. Neave. 2021. Symposium review: Precision technologies for dairy calves and management ap- plications. J. Dairy Sci. 104:1203-1219. https://doi.org/10.3168/ jds.2019-17885.

Costa, J. H. C., M. A. G. von Keyserlingk, and D. M. Weary. 2016. Invited review: Effects of group housing of dairy calves on behavior, cognition, performance, and health. J. Dairy Sci. 99:2453-2467. https://doi.org/10.3168/jds.2015-10144.

Cramer, M. C., and T. L. Ollivett. 2019. Growth of preweaned, grouphoused dairy calves diagnosed with respiratory disease using clinical respiratory scoring and thoracic ultrasound - A cohort study. J. Dairy Sci. 102:4322-4331. https://doi.org/10.3168/jds.2018-15420.

Cramer, C., K. Proudfoot, and T. Ollivett. 2020. Automated feeding behaviors associated with subclinical respiratory disease in preweaned dairy calves. Animals (Basel) 10:988. https://doi.org/10 $.3390 /$ ani10060988.

Cramer, M. C., and A. L. Stanton. 2015. Associations between health status and the probability of approaching a novel object or stationary human in preweaned group-housed dairy calves. J. Dairy Sci. 98:7298-7308. https://doi.org/10.3168/jds.2015-9534.

de Passillé, A. M., M. Rabeyrin, and J. Rushen. 2016. Associations between milk intake and activity in the first days of a calf's life and later growth and health. Appl. Anim. Behav. Sci. 175:2-7. https:/ /doi.org/10.1016/j.applanim.2014.10.002.

De Paula Vieira, A., V. Guesdon, A. M. de Passillé, M. A. G. von Keyserlingk, and D. M. Weary. 2008. Behavioural indicators of hunger in dairy calves. Appl. Anim. Behav. Sci. 109:180-189. https://doi .org/10.1016/j.applanim.2007.03.006.

Dunn, T. R., T. L. Ollivett, D. L. Renaud, K. E. Leslie, S. J. LeBlanc, T. F. Duffield, and D. F. Kelton. 2018. The effect of lung consolidation, as determined by ultrasonography, on first-lactation milk production in Holstein dairy calves. J. Dairy Sci. 101:5404-5410. https://doi.org/10.3168/jds.2017-13870.

Gargon, E., S. L. Gorst, and P. R. Williamson. 2019. Choosing important health outcomes for comparative effectiveness research: 5th annual update to a systematic review of core outcome sets for research. PLoS One 14:e225980. https://doi.org/10.1371/journal .pone.0225980.

Groutides, C. P., and A. R. Michell. 1990. Intravenous solutions for fluid therapy in calf diarrhoea. Res. Vet. Sci. 49:292-297. https:// doi.org/10.1016/0034-5288(90)90062-9.

Jensen, M. B., and L. Holm. 2003. The effect of milk flow rate and milk allowance on feeding behaviour in dairy calves fed by computer controlled milk feeders. Appl. Anim. Behav. Sci. 82:87-100. https://doi.org/10.1016/S0168-1591(03)00054-6.

Johnson, R. W. 2002. The concept of sickness behavior: A brief chronological account of four key discoveries. Vet. Immunol. Immunopathol. 87:443-450. https://doi.org/10.1016/S0165-2427(02)00069 $-7$.

Johnson, P. C. D., S. J. E. Barry, H. M. Ferguson, and P. Müller. 2015. Power analysis for generalized linear mixed models in ecology and evolution. Methods Ecol. Evol. 6:133-142. https://doi.org/ 10.1111/2041-210X.12306.

Johnston, D., D. A. Kenny, M. McGee, S. M. Waters, A. K. Kelly, and B. Earley. 2016. Electronic feeding behavioural data as indicators of health status in dairy calves. Ir. J. Agric. Food Res. 55:159-168. https://doi.org/10.1515/ijafr-2016-0016.

Jorgensen, M. W., A. Adams-Progar, A. M. de Passille, J. Rushen, S. M. Godden, H. Chester-Jones, and M. I. Endres. 2017. Factors associated with dairy calf health in automated feeding systems in the Upper Midwest United States. J. Dairy Sci. 100:5675-5686. https: //doi.org/10.3168/jds.2016-12501.

Knauer, W. A., S. M. Godden, A. Dietrich, and R. E. James. 2017. The association between daily average feeding behaviors and morbidity in automatically fed group-housed preweaned dairy calves. J. Dairy Sci. 100:5642-5652. https://doi.org/10.3168/jds.2016-12372.

Knauer, W. A., S. M. Godden, A. Dietrich, D. M. Hawkins, and R. E. James. 2018. Evaluation of applying statistical process control techniques to daily average feeding behaviors to detect disease in automatically fed group-housed preweaned dairy calves. J. Dairy Sci. 101:8135-8145. https://doi.org/10.3168/jds.2017-13947.

Langford, F. M., D. M. Weary, and L. Fisher. 2003. Antibiotic resistance in gut bacteria from dairy calves: A dose response to the 
level of antibiotics fed in milk. J. Dairy Sci. 86:3963-3966. https:/ /doi.org/10.3168/jds.S0022-0302(03)74006-5.

Levac, D., H. Colquhoun, and K. K. O'brien. 2010. Scoping studies: Advancing the methodology. Implement. Sci. 5:69. https://doi .org/10.1186/1748-5908-5-69.

Liberati, A., D. G. Altman, J. Tetzlaff, C. Mulrow, P. C. Gøtzsche, J. P. A. Ioannidis, M. Clarke, P. J. Devereaux, J. Kleijnen, and D. Moher. 2009. The PRISMA statement for reporting systematic reviews and meta-analyses of studies that evaluate health care interventions: Explanation and elaboration. PLoS Med. 6:e1000100. https://doi.org/10.1371/journal.pmed.1000100.

Maatje, K., J. Verhoeff, W. D. J. Kremer, A. L. M. Cruijsen, and T. S. G. A. M. van den Ingh. 1993. Automated feeding of milk replacer and health control of group-housed veal calves. Vet. Rec. 133:266-270. https://doi.org/10.1136/vr.133.11.266.

McGuirk, S. M. 2008. Disease management of dairy calves and heifers. Vet. Clin. North Am. Food Anim. Pract. 24:139-153. https://doi .org/10.1016/j.cvfa.2007.10.003.

McGuirk, S. M., and S. F. Peek. 2014. Timely diagnosis of dairy calf respiratory disease using a standardized scoring system. Anim. Health Res. Rev. 15:145-147. https://doi.org/10.1017/ S1466252314000267.

Medrano-Galarza, C., S. J. LeBlanc, T. J. DeVries, A. Jones-Bitton, J. Rushen, A. M. de Passillé, and D. B. Haley. 2017. A survey of dairy calf management practices among farms using manual and automated milk feeding systems in Canada. J. Dairy Sci. 100:6872-6884. https://doi.org/10.3168/jds.2016-12273.

Medrano-Galarza, C., S. J. LeBlanc, A. Jones-Bitton, T. J. DeVries, J. Rushen, A. Marie de Passille, M. I. Endres, and D. B. Haley. 2018. Associations between management practices and within-pen prevalence of calf diarrhea and respiratory disease on dairy farms using automated milk feeders. J. Dairy Sci. 101:2293-2308. https: //doi.org/10.3168/jds.2017-13733.

Morrison, J., and D. L. Renaud. M. A. Steele., J. H. C. Costa., and C. B. Winder. 2019. Investigating the use of automated feeder data as potential predictors of morbidity and mortality in pre-weaned dairy calves: A scoping review protocol. Accessed Sep. 6, 2019. http://hdl.handle.net/10214/17262.

Ollivett, T. L., and S. Buczinski. 2016. On-farm use of ultrasonography for bovine respiratory disease. Vet. Clin. North Am. Food Anim. Pract. 32:19-35. https://doi.org/10.1016/j.cvfa.2015.09.001.

Rosenberger, K., J. H. C. Costa, H. W. Neave, M. A. G. von Keyserlingk, and D. M. Weary. 2017. The effect of milk allowance on behavior and weight gains in dairy calves. J. Dairy Sci. 100:504-512. https://doi.org/10.3168/jds.2016-11195.

Roth, B. A., N. M. Keil, L. Gygax, and E. Hillmann. 2009. Influence of weaning method on health status and rumen development in dairy calves. J. Dairy Sci. 92:645-656. https://doi.org/10.3168/ jds.2008-1153.

Sargeant, J. M., B. Deb, M. D. Bergevin, K. Churchill, K. Dawkins, J. Dunn, D. Hu, C. Moody, A. M. O'Connor, T. L. O'Sullivan, M. Reist, C. Wang, B. Wilhelm, and C. B. Winder. 2019. Efficacy of bacterial vaccines to prevent respiratory disease in swine: A systematic review and network meta-analysis. Anim. Health Res. Rev. 20:274-290. https://doi.org/10.1017/S1466252319000173.

Sivula, N. J., T. R. Ames, W. E. Marsh, and R. E. Werdin. 1996. Descriptive epidemiology of morbidity and mortality in Minnesota dairy heifer calves. Prev. Vet. Med. 27:155-171. https://doi.org/10 .1016/0167-5877(95)01000-9.

Sutherland, M. A., G. L. Lowe, F. J. Huddart, J. R. Waas, and M. Stewart. 2018. Measurement of dairy calf behavior prior to onset of clinical disease and in response to disbudding using automated calf feeders and accelerometers. J. Dairy Sci. 101:8208-8216. https: //doi.org/10.3168/jds.2017-14207.

Svensson, C., and J. Hultgren. 2008. Associations between housing, management, and morbidity during rearing and subsequent first lactation milk production of dairy cows in southwest Sweden. J. Dairy Sci. 91:1510-1518. https://doi.org/10.3168/jds.2007-0235.

Svensson, C., and M. B. Jensen. 2007. Short communication: Identification of diseased calves by use of data from automatic milk feed- ers. J. Dairy Sci. 90:994-997. https://doi.org/10.3168/jds.S0022 -0302(07)71584-9.

Svensson, C., K. Lundborg, U. Emanuelson, and S. O. Olsson. 2003. Morbidity in Swedish dairy calves from birth to 90 days of age and individual calf-level risk factors for infectious diseases. Prev. Vet. Med. 58:179-197. https://doi.org/10.1016/s0167-5877(03)00046-1.

Swartz, T. H., A. N. Findlay, and C. S. Petersson-Wolfe. 2017. Automated detection of behavioral changes from respiratory disease in pre-weaned calves. J. Dairy Sci. 100:9273-9278. https://doi.org/10 .3168/jds.2016-12280.

ter Riet, G., and L. Bouter. 2016. How to end selective reporting in animal research. Pages 61-78 in Animal Models for Human Cancer: Discovery and Development of Novel Therapeutics. M. I. Martic-Kehl and P. A. Schubiger, ed. Wiley, Hoboken, NJ.

Tricco, A. C., E. Lillie, W. Zarin, K. K. O'Brien, H. Colquhoun, D. Levac, D. Moher, M. D. J. Peters, T. Horsley, L. Weeks, S. Hempel, E. A. Akl, C. Chang, J. McGowan, L. Stewart, L. Hartling, A. Aldcroft, M. G. Wilson, C. Garritty, S. Lewin, C. M. Godfrey, M. T. Macdonald, E. V. Langlois, K. Soares-Weiser, J. Moriarty, T. Clifford, O. Tuncalp, and S. E. Straus. 2018. PRISMA extension for scoping reviews (PRISMA-ScR): Checklist and explanation. Ann. Intern. Med. 169:467-473.

Uetake, K. 2013. Newborn calf welfare: A review focusing on mortality rates. Anim. Sci. J. 84:101-105. https://doi.org/10.1111/asj .12019 .

Urie, N. J., J. E. Lombard, C. B. Shivley, C. A. Kopral, A. E. Adams, T. J. Earleywine, J. D. Olson, and F. B. Garry. 2018a. Preweaned heifer management on US dairy operations: Part I. Descriptive characteristics of preweaned heifer raising practices. J. Dairy Sci. 101:9168-9184. https://doi.org/10.3168/jds.2017-14010.

Urie, N. J., J. E. Lombard, C. B. Shivley, C. A. Kopral, A. E. Adams, T. J. Earleywine, J. D. Olson, and F. B. Garry. 2018b. Preweaned heifer management on US dairy operations: Part V. Factors associated with morbidity and mortality in preweaned dairy heifer calves. J. Dairy Sci. 101:9229-9244. https://doi.org/10.3168/jds .2017-14019.

Webb, L. E., C. G. van Reenen, H. Berends, B. Engel, I. J. M. de Boer, W. J. J. Gerrits, and E. A. M. Bokkers. 2015. The role of solid feed amount and composition and of milk replacer supply in veal calf welfare. J. Dairy Sci. 98:5467-5481. https://doi.org/10.3168/ jds.2014-8547.

Wenge, J., I. Steinhöfel, C. Heinrich, M. Coenen, and L. Bachmann. 2014. Water and concentrate intake, weight gain and duration of diarrhea in young suckling calves on different diets. Livest. Sci. 159:133-140. https://doi.org/10.1016/j.livsci.2013.11.004.

Winder, C. B., C. A. Bauman, T. F. Duffield, H. W. Barkema, G. P. Keefe, J. Dubuc, F. Uehlinger, and D. F. Kelton. 2018. Canadian National Dairy Study: Heifer calf management. J. Dairy Sci. 101:10565-10579. https://doi.org/10.3168/jds.2018-14680.

Winder, C. B., K. J. Churchill, J. M. Sargeant, S. J. LeBlanc, A. M. O'Connor, and D. L. Renaud. 2019. Invited review: Completeness of reporting of experiments: REFLECTing on a year of animal trials in the Journal of Dairy Science. J. Dairy Sci. 102:4759-4771. https://doi.org/10.3168/jds.2018-15797.

Windeyer, M. C., K. E. Leslie, S. M. Godden, D. C. Hodgins, K. D. Lissemore, and S. J. LeBlanc. 2014. Factors associated with morbidity, mortality, and growth of dairy heifer calves up to 3 months of age. Prev. Vet. Med. 113:231-240. https://doi.org/10.1016/j .prevetmed.2013.10.019.

\section{ORCIDS}

Jannelle Morrison ( https://orcid.org/0000-0001-9092-2452 David L. Renaud ๑ https://orcid.org/0000-0002-3439-3987 Joao H. C. Costa (®) https://orcid.org/0000-0001-9311-4741 Michael A. Steele ๑ https://orcid.org/0000-0001-6941-6205 Charlotte B. Winder (ํ) https://orcid.org/0000-0002-7314-3657 